\title{
Energy Metabolism Regulating Mammalian Oocyte Maturation
}

\author{
N. Songsasen \\ Department of Reproductive Sciences, Center for Species Survival, \\ Smithsonian Conservation Biology Institute, Front Royal, \\ Virginia
}

\section{Introduction}

Oocyte maturation is a final step of gamete development that follows a prolonged period of cell growth within a growing follicle. Unlike oocyte growth that takes several weeks or months, maturation process is a short (hours or days), dynamic process. The period of oocyte maturation varies among species, ranging from 10-13 hours in the mouse (Edwards \& Gates, 1959) to 16-24 hours in the cow (Dominko \& First, 1997) and $48-72$ hours in the dog (Reynaud et al., 2005, Songsasen \& Wildt, 2007). For an oocyte to fully capable of fertilizing and developing into an embryo, the gamete needs to undergo nuclear and cytoplasmic maturation. Nuclear maturation encompasses events associated with the separation of homologous chromosomes during meiosis I and the segregation of sister chromatids during meiosis 2 (Albertini \& Limback, 2009). Events occur during this process include nuclear envelope breakdown, rearrangement of the cortical cytoskeleton and meiotic spindle assembly. Cytoplasmic maturation includes events of post-transcriptional and posttranslational processes, including mRNA synthesis, rearrangement of cytoplasmic organelles and glutathione production that are essential for successful fertilization and subsequent embryonic development (Albertini \& Limback, 2009, Watson, 2007). For an oocyte to appropriately progress to these dynamic process of nuclear and cytoplasmic maturation, it requires enormous energy from various substrates, including glucose, amino acids and lipids (Sutton et al., 2003). In addition, tight regulation of reactive oxygen species (ROS) and calcium homeostasis are important during this process. This chapter will review current knowledge on mammalian oocyte development, the roles of mitochondria on cell functions and energy metabolism and its impact on gamete maturation.

\section{Mammalian oocyte development}

The oocyte arises from the primordial germ cells (PGCs) developed during the embryogenesis (Edson et al., 2009). Once formed, the PGCs proliferate and migrate to the undifferentiated gonad that later becomes the ovary. Within the gonad, PGCs enter mitosis with incomplete cytokinesis to form clusters of germ cell nest consisting of oogonia connected to each other by intercellular bridges (Tingen et al., 2009), and the syncytia units are surrounded by pre-granulosa and stromal mesenchymal cells of the ovary. Oogenesis occurs in utero in rodents, ruminants and primates, whereas that of the cat, dog and ferret 
takes place after birth (Peter \& McNatty, 1980). During this process, oogonia within germ cell nests transform into the oocytes by, albeit asynchronously, entering the first meiotic prophase and being arrested at the late diplotene stage. The interval between the appearance of the first and the last oocytes within the ovary varies greatly among species, ranging from 2 days in the rat to 5 months in the human (Peter \& McNatty, 1980).

Formation of the primordial follicle begins during the fetal life in the human, monkey, horse, cow and pig, but not until during neonatal period in the mouse and rat or later in the second or third weeks after birth in cats, dogs, ferrets, rabbits and minks (Peter \& McNatty, 1980). Primordial follicle formation begins with the breakdown of germ cell nest involving the degeneration of vast numbers of oocytes and the invasion of pre-granulosa cells into the germ cell syncytia (Tingen et al., 2009). The loss of oocytes during germ cell nest breakdown is substantial and is believed to be part of quality control processes to ensure that only healthy oocytes are enclosed inside primordial follicles (Tingen et al., 2009). It has been suggested that genetic defects or the failure of germ cells to produce mitochondria are responsible for selective loss of oocytes during the nest breakdown process (Tingen et al., 2009). The surviving oocytes are individually surrounded by squamous pre-granulosa cells and the entire unit is referred to as the primordial follicle (Edson et al., 2009). To date, it has been suggested that several factors produced by the oocytes and somatic cells, including synaptonemal complex protein, Fox12, NOBOX, members of Notch signaling pathway and transforming growth factor family play roles in germ cell nest breakdown and formation of primordial follicles (Tingen et al., 2009).

Most primordial follicles ( $90 \%$ ) leave the resting pool via apoptosis, while the remainders are activated by poorly understood mechanisms to enter the growing follicle pool and develop into the primary, secondary and antral stage (Gougeon, 2010, Picton, 2001). During the early stage of follicle development, the oocyte rapidly increases in size; however, as folliculogenesis proceeds, the growth rate significantly decline and the gamete reaches the maximum size shortly after antral formation (Griffin et al., 2006, Reynaud et al., 2009, Songsasen et al., 2009). During oocyte growth, several organelles including, mitochondria, endoplasmic reticulum and golgi complexes become more abundant (Peter \& McNatty, 1980), indicating that energy production and protein synthesis are essential during this process. In most mammalian species, the oocyte resumes meiosis in the preovulatory follicle shortly before ovulation. However, meiotic resumption occurs after the dog oocyte is released from the follicle (Songsasen \& Wildt, 2007). At the initiation of meiotic resumption, the nucleus of the oocyte migrates from the central position to the periphery of the cell, and the nuclear membrane and nucleoli disappear as the chromosomes become condensed. This stage is referred to as germinal vesicle breakdown (GVBD). The GVBD oocyte progresses to the metaphase I (MI) stage as the chromosomes are firmly attached to the meiotic spindle. This stage is followed by the separation of homologous chromosomes; one set remain in the secondary oocyte and another set move into a small portion of cytoplasm that is extruded as the second polar body. The chromosomes within the secondary oocyte resume metaphase configuration (i.e., metaphase II [MII] stage) which remains until fertilization. Completion of meiosis occurs after a spermatozoon penetrating the oocyte. During this process, the gamete extrudes the secondary polar body. The remaining chromosomes are enclosed in the nuclear membrane and forming female pronucleus that later fuses with the male counterpart to become the zygote. During its developmental process, the oocyte is coupled to the surrounding granulosa cells through trans-zonal processes (Eppig et al., 1996). This intimate 
physical connection is crucial for follicle and oocyte development as it facilitates bidirectional communication between the gamete and the somatic cells via gap junction and paracrine signaling (Eppig et al., 1996).

\section{Mitochondria are the key organelles regulating cell functions}

The mitochondria are characterized by having double membranes and their own DNA (mtDNA) inherited from the maternal origin (Van Blerkom, 2004). These organelles play fundamental roles in cell functions, including, providing energy, regulating apoptotic pathway and $\mathrm{Ca}^{2+}$ homeostasis (Van Blerkom, 2004, Ramalho-Santos et al., 2009). Dysfunction of mitochondria has been linked to several pathologies, such as heart diseases (Facecchia et al., 2011; Perrelli, et al. 2011), neurodegenerative (Facecchia et al., 2011) and infertility (Ramalho-Santos et al., 2009). The mitochondria provide ATP to cells via oxidative phosphorylation. During this process, high energy electrons derived from oxidation are carried by $\mathrm{NADH}+\mathrm{H}^{+}$and $\mathrm{FADH}_{2}$ to the inner mitochondrial membrane and transferred through cascades of electron transport chain that convert the electrons into ATP (RamalhoSantos et al., 2009; Voet \& Voet, 2004).

Mitochondria also participate in apoptotic pathways (Ramalho-Santos et al., 2009). Because mitochondria consume $\sim 85 \%$ of cell's oxygen, these organelles are major producers of ROS (Ramalho-Santos et al., 2009). Excessive production of ROS can lead to DNA damage (especially mtDNA), oxidation of proteins and lipid, as well as release of cytochrome B into the extramitochondrial milieu (Ott et al., 2007). The release of cytochrome B into the cytosol triggers a series of events leading to proteolytic enzyme activation, including caspase 3, 6 and 7 that regulate cell death (Ott et al., 2007). Therefore, cells critically depend on the tight regulation of mitochondrial redox balance to maintain viability and proper functions. It has been shown that glutathione (GSH) and GSH-linked antioxidant enzymes, including Gpx1 and 4 play important roles in maintaining mitochondrial redox balance (Ott et al., 2007). Specifically, these enzymes catalyze the reduction of hydrogen peroxide and lipid peroxide (into $\mathrm{H}_{2} \mathrm{O}$ ) with GSH serves as the electron donor. Furthermore, mitochondrial thioredoxin has been shown to play roles in maintaining mitochondria protein in their reduce state, that in turn counter the reaction of ROS (Ott et al., 2007).

During folliculogenesis and oogenesis, mitochondria propagate simultaneously with the increase in cytoplasmic volume. Pre-migratory PGCs have $<10$ mitochondria (Van Blerkom, 2004). However, the numbers of mitochondria within the germ cells increase 10 -fold by the time PGCs reach the ovary and additional 2-fold after transformation into the oocyte. Primordial follicle oocytes contain 10,000 mitochondria which increase to 100,000 in mature gametes (Ramalho-Santos et al., 2009). The increase in number of mitochondria also coincides with changes in the distribution of the organelles (Rmalho-Santos et al., 2009). Specifically, mitochondria surround the nucleus in the primary follicle. As the follicle developing into secondary stage, mitochondria within the oocyte distribute throughout the cytoplasm (Peter \& McNatty, 1980). In fully grown-germinal vesicle oocyte, the mitochondria homogenously distribute throughout the cell with some localization at the periphery (Sun et al., 2001). As the oocyte progresses through meiotic maturation, mitochondria relocate into the perinuclear region and aggregate into cluster (Yu et al., 2010; Van Blerkom et al., 2002; Sturmey et al., 2006); this event coincides with the rise in ATP levels (Yu et al., 2010). Therefore, the change in localization of mitochondria during oocyte 
growth is probably in response to energy demand during a given stage of development (Ramalho-Santos et al., 2009).

The oocyte contains two populations of mitochondria which differ in polarization (i.e., electrical and chemical gradient $\left.\left[\Delta \Psi_{\mathrm{M}}\right]\right)$; one which is more abundant has low $\Delta \Psi_{\mathrm{M}}$ and the smaller population is highly polarized (Ramalho-Santos et al., 2009; Acton et al., 2004, Van Blerkom et al., 2003). In mouse and human oocytes, highly polarized mitochondria are clustered in pericortical cytoplasm probably to (1) maintain sufficient ATP production in the sub-plasmalemma region in the preparation for fertilization and (2) play role in $\mathrm{Ca}^{2+}$ regulation during oocyte activation (Ramalho-Santos et al., 2009; Van Blerkom et al., 2003; Van Blerkom \& Davis, 2007). It also has been shown that mitochondrial polarity is associated with developmental capacity of the oocyte and embryo (Van Blerkom, 2004; Acton et al., 2004; Van Blerkom \& Davis, 2007; Fujii \& Funahashi, 2009). Specifically, mitochondrial membrane potential (MMP) increases as oocytes progress through meiotic maturation (Fujii \& Funahashi, 2009), and inhibition of MMP rise decreases the ability of the gamete to form pronucleus and impairs embryonic development (Fujii \& Funahashi, 2009).

\section{Glucose is a key substrate for providing energy during oocyte maturation}

Glucose metabolism is crucial for oocyte maturation and development post-fertilization in many mammalian species (Sutton-McDowall et al., 2010; Krisher et al., 2007). In vitro culture of oocytes in sub-optimal concentrations of glucose results in delayed meiotic maturation, fertilization and embryonic development (Sutton-McDowall et al., 2010; Sato et al., 2007; Zheng et al., 2001). Delayed resumption of meiosis in prepubertal cattle oocytes is associated with retarded glucose metabolism (Steeves \& Gardner, 1999). Furthermore, pharmacological stimulation of glucose metabolism enhances the developmental competence of cow (Krisher \& Bavister, 1999) and pig (Herrick et al., 2006) oocytes in vitro. Finally, it has been shown that diabetic mice experience abnormal cellular metabolism, mitochondrial dysfunction and meiotic defect (Wang et al., 2010; Colton, et al., 2002).

Glucose uptake into the oocyte occurs via facilitative glucose transporters (GLUT) in the mouse (Purcell \& Moley, 2009), cow (Augustin et al., 2001), sheep (Pisani et al., 2008), human (Dan Goor et al., 1997) and rhesus monkey (Zheng et al., 2007). But mammalian oocytes also have low capacity to utilize this substrate (Sutton-McDowall et al., 2010; Steeves \& Gardner, 1999; Purcell \& Moley, 2009, Brinster, 1971), possibly due to having limited amount of a glycolytic enzyme phosphofructokinase (Cetica et al., 2002). Thus, most mammalian species appear to rely on cumulus cells that contain an additional GLUT with high affinity to this substrate and high phosphofructokinase activity to convert glucose into readily utilized substrates (i.e., pyruvate, NADPH; (Sutton-McDowall et al., 2010; Biggers, et al., 1967). However, we have recently found that dog oocytes utilize glucose at a much higher rate than that of other species (Songsasen et al., 2012). This finding indicates that dog gamete may contain additional GLUT or high levels of glycolytic enzyme compared to those in other species.

The cumulus-oocyte complexes (COCs) have been found to metabolize glucose through four pathways, including glycolysis, the pentose-phosphate- (PPP), hexoxamine (HBP)- and polyol pathways (Sutton-McDowall et al., 2010), with the first two known to affect nuclear and cytoplasmic maturation of mouse (Downs, 1995), pig (Herrick et al., 2006; Krisher et al., 
2007), cow (Krisher et al., 2007; Steeves \& Gardner, 1999, Rieger \& Loskutoff, 1994) and cat (Spindler et al., 2000) oocytes.

COCs utilize substantial amount of glucose via glycolytic pathway produces energy (ATP), pyruvate and lactate. Pyruvate and lactate then enter the oocyte and are metabolized via the tricarboxylic pathway (TCA) followed by oxidative phosphorylation within the mitochondria that produce substantial amount of ATP essential for oocyte development. Glycolytic metabolism has been shown to play key roles in developmental competence of cow (Steeves \& Gardner, 1999, Rieger \& Loskutoff, 1994), cat (Spindler et al., 2000) and pig oocytes (Herrick et al., 2006). Specifically, glucose metabolism increases as immature cat oocytes progress through meiotic maturation from the GV to MII stage (Spindler et al., 2000). These same investigators also demonstrated that developmental competence postfertilization, including the ability to advance to the blastocyst embryos, directly depended on glycolytic rate.

Although PPP does not generate ATP, this pathway generates NADPH that is essential for cytoplasmic integrity and GSH production (Sutton-McDowall et al., 2010; Garcia, et al., 2010). Furthermore, PPP produces ribose-5-phosphate that is critical for DNA and RNA syntheses (Sutton-McDowall et al., 2010; Krisher et al., 2007; Newsholme, et al., 2003). It has been shown the mouse oocyte preferentially metabolize glucose via this pathway. Stimulation of the PPP in mouse oocytes significantly increases GVBD due to conversion of ribose-5 phosphate to phosphoribosyl pyrophosphate that is involved in the production of purine nucleotides, important precursors of DNA and RNA synthesis (Downs et al., 1998). PPP also plays roles in completion of meiosis after fertilization via production of NADPH followed by generation of ROS essential for signaling pathways (Urner \& Sakkas, 2005). In the pig, PPP plays critical role in resumption of meiosis and transition of GVBD to MII stage oocytes (Sato et al., 2007; Herrick et al., 2006; Funahashi et al., 2008). Inhibiting PPP activity decreases glycolysis and production of GSH that, in turn compromise oocyte developmental potential in this species (Herrick et al.,2006).

Follicle stimulating hormone (FSH) is the primary regulator of ovarian folliculogenesis (Gougeon, 2010). FSH has been shown to support meiotic resumption by promoting glucose metabolism in mouse oocyte. Specifically, FSH increases glucose uptake (Roberts et al., 2004), as well as promotes glycolysis and PPP in the mouse (Downs \& Utecht, 1999), and augment TCA in the cow (Zuelke \& Brackett, 1992). Luteinizing hormone surge (LH) plays significant roles in meiotic maturation of mammalian oocytes (Gougeon, 2010; Son et al., 2011, Hsieh et al., 2011). LH surge causes a significant decline in gap junctions leading to dissociation of granulosa cells from the gamete and expansion of the cumulus cells. LH also activates its G-protein-coupled receptor on theca and granulosa cells, which in turn leads to elevation of intracellular cAMP that subsequently triggers multiple downstream pathways regulating meiotic maturation and ovulation (Hsieh et al., 2011, Sun et al., 2009). Finally, LH promotes cow oocytes maturation by modifying gamete's nutritional microenvironment via increasing glucose utilization through glycolysis and TCA cycle (Zuelke \& Brackett, 1992).

\section{Amino acids influence cell functions}

Amino acids play important roles in cellular functions, as they serve as substrates for protein synthesis, energy production, organic osmolytes and intracellular buffer (Sutton et 
al., 2003; Bae \& Foote, 1974). Furthermore, cysteine, proline and glutamine are precursors of GSH (Sutton et al., 2003). It has been shown that there are differences in amino acid composition within follicular fluid among species. Hystinine, phynylalanine, asparagines and glutamate are present in high concentrations in human follicular fluid (Jozwik et al., 2006; Jimena, et al., 1993). However, glycine, glutamine and alanine are most abundant in the cow (Orsi et al., 2005). Finally, glycine, alanine and serine, and glutamine, glycine and aspartate are found in high concentration in horses (Engle et al., 1984) and mice (Harris et al., 2005), respectively. These apparent differences in follicular amino acids composition among species suggest that there are variations in amino acid requirement during oocyte maturation among various taxa.

Amino acid concentrations fluctuate with ovarian follicle development. Specifically, in the pig, most amino acids are present in lower concentration in large follicles than in small counterparts (Hong \& Lee, 2007). This may be attributed to the decrease in the amount of specific amino acids following preferred consumption by follicular cells or oocytes during follicular development. Culturing pig oocytes in the presence of glutamine, aspargine and valine enhances cytoplasmic maturation based on the improvement of monospermic fertilization and embryonic development (Hong \& Lee, 2007). Furthermore, addition of essential amino acids to chemically defined maturation media enhances oocyte maternal mRNA synthesis, embryo developmental rates and cell numbers in blastocyst embryos in the cow (Watson et al., 2000).

Mammalian oocytes utilize amino acids via the cumulus cells. Cumulus cells contain high concentration of two essential enzymes for amino acid metabolism, alanine aminotransferase [ALT] and aspartate aminotransferase [AST] (Cetica, et al., 2003), suggesting that the somatic cells supplies the oocyte with amino acid or oxidative substrate. Because oocytes also possess ALT and AST activities, albeit lower than cumulus cells, they continue to utilize amino acids after being dissociated from the somatic cells during maturation (Cetica et al., 2003).

Glutamine is the most widely studied amino acid among those found in follicular fluid. This amino acid is recognized as a key substrate for GSH synthesis, protein translation and gluconeogenesis (Bae \& Foote 1974; Newsholme et al. 2003). In cattle, glutamine metabolism through the TCA cycle increases steadily during oocyte maturation and reaches maximum at 18 to 24 of in vitro culture (Steeves \& Gardner, 1999; Rieger \& Loskutoff, 1994). This finding suggests that this amino acid is critical for promoting final nuclear maturation in this species (Rieger \& Loskutoff, 1994). Addition of glutamine to maturation medium increases the number of cow oocytes completing nuclear maturation (Bilodeau-Goeseels, 2006). However, supplement culture medium with glutamine alone does not improve developmental competence of rhesus monkey oocytes (Zheng et al., 2002). Nevertheless, combination of glutamine and 20 amino acids enhances nuclear maturation in this species (Zheng et al., 2002). It has been shown that glutamine is an effective energy substrate to support rabbit oocyte maturation (Bae \& Foote, 1974). Our earlier study demonstrates that glutamine uptake peaks at about $12 \mathrm{~h}$ after the onset of culturing dog oocytes (Songsasen et al., 2007), suggesting its role in meiotic resumption in this species. However, addition of glutamine to a culture medium does not improve nuclear maturation rate, suggesting that this amino acid plays role in cytoplasmic maturation in the dog (Songsasen et al., 2007). In the mouse, the use of glutamine as a sole energy source (i.e., without carbohydrate 
supplementation) is sufficient to initiate meiotic resumption, but not enough to support the transition of GVBD to MII oocytes (Downs \& Hudson, 2000). Gonadotropins have been shown to promote glutamine metabolism. Specifically, in the presence of FSH, glutamine promotes nuclear maturation of hamster oocytes (Kito \& Bavister, 1997). LH stimulates cumulus cells to convert glutamine to $\alpha$-ketoglutarate, which is then oxidized through TCA cycle to generate ATP (Zuelke \& Brackett, 1993).

\section{Lipids are important endogenous energy source during oocyte maturation}

Intracellular lipids play essential roles in oocyte development (Sturmey et al., 2009, 2006; Sturmey \& Leese, 2003; Ferguson \& Leese, 2006). Lipids serve as reservoir of endogenous energy source, substrates for water production during blastocoel development and precursors of second messengers modulating cell functions and purine synthesis (McEvoy et al., 2000). Furthermore, membrane bound phospholipids regulate various cell functions associated with calcium flux (e.g., cortical granule exocytosis and fertilization (McEvoy et al., 2000).

Mammalian oocytes contain an endogenous lipid reserve that varies in quantity among species (ranging from $4 \mathrm{ng}$ total lipid per oocyte (Loewenstein \& Cohen, 1964) in the mouse to $63 \mathrm{ng}$ (McEvoy et al., 2000) in the cow to $161 \mathrm{ng}$ the pig (Sturmey \& Leese, 2003; McEvoy et al., 2000). Triglyceride is the main lipid found in mammalian oocytes (range for $30 \%$ in sheep to $60 \%$ of total lipid in pig) (Sturmey \& Leese, 2003; Sturmey et al., 2009; Ferguson \& Leese, 1999). It has been shown that triglyceride stores decrease as cows (Leese \& Ferguson, 1999) and pigs (Sturmey \& Leese, 2003) oocytes progress through meiotic maturation, and this process is coincides with increased lipolysis (Cetica et al., 2002). These findings indicate that triglyceride provides a rich energy supply for oocyte maturation (Cetica et al., 2002) and sustaining pre-implantation embryo growth (Sturmey et al., 2006, Ferguson \& Leese, 2006). Sturmey et al. (2006) utilized the fluorescence resonance energy transfer technology to examine the relationship between mitochondria and cytoplasmic lipid droplets during pig oocyte maturation and reported that the two organelles co-localize in a molecular level and form 'metabolic units' at the periphery of the gamete. There are evidence indicating that free fatty acids cleaved from triglyceride molecules stored in lipid droplets can be directly transported across the mitochondrial membrane and oxidized via $\beta$-oxidation that results in the production of acetyl CoA, a substrate for the TCA cycle (Sturmey et al., 2006; Dunning et al., 2010). Culturing pig and cow oocytes (Ferguson \& Leese, 2006) in the presence of an inhibitor of carnitine palmitoyl transferase, the enzyme responsible for the transport of free fatty acids into the mitochondrial matrix compromises embryo development postfertilization (Sturmey et al., 2006). Enhancing lipid metabolism and mitochondrial activity by addition of L-carnitine to culture medium decreases ROS levels, as well as improves MII and cleavage rates (Somfai et al., 2011), although the treatment does not impact blastocyst formation. In the mouse, $\beta$-oxidation is significantly up-regulated during both in vivo and in vitro oocyte maturation (Dunning et al., 2010). Inhibition of $\beta$-oxidation compromises meiotic resumption (Downs et al., 2009) and impairs embryonic development formation following fertilization (Dunning et al., 2010), suggesting that lipid metabolism plays essential roles in both nuclear and cytoplasmic maturation in the mouse. Furthermore, enhancing $\beta$-oxidation by supplement L-carnitine to the culture medium during in vitro follicle culture and in vitro maturation significantly improves mouse oocyte developmental competence (Dunning et al., 2011, 2010). 


\section{Species specificity in preferentially differences in energy substrate}

To date, studies have revealed that there are species-specific energy requirement for oocyte maturation. Mouse oocytes require exogenous energy substrate (especially pyruvate) to complete nuclear maturation (Downs \& Hudson, 2000) probably due to the limited amount of intracellular lipid (Loewenstein \& Cohen, 1964). Mouse oocytes cultured in the absence of glucose and pyruvate fail to progress to the MII stage (Downs \& Hudson, 2000). In contrast, cow oocytes which contain 20 fold of total lipid mass compared to the mouse are able to complete nuclear maturation in the absence of exogenous energy substrates (Sturmey et al., 2009). Furthermore, inhibition of triglyceride metabolism compromises nuclear maturation in this species (Ferguson \& Leese, 2006).

Mouse (Sturmey et al., 2009; Downs et al., 2002; Downs \& Mastropolo, 1994; Biggers et al., 1967), cow (Steeves \& Gardner, 1999) and cat oocytes (Spindler et al., 2000) appear to prefer pyruvate to glucose as an energy source. Pyruvate supports maturation, maintains viability and promotes cleavage of the fertilized oocyte in the absence of cumulus cells (Downs et al., 2002; Downs \& Mastropolo, 1994; Biggers et al., 1967). The metabolism of pyruvate is related to the stage of meiosis, with arrested oocytes (GV or MII) metabolizing less pyruvate than oocytes progressing through meiosis (Downs et al., 2002). Cow oocytes utilize pyruvate produced by the cumulus cell via glycolysis (Cetica et al., 2002). Furthermore, cow oocytes have more G6PDH than phosphofructokinase, suggesting that the gamete preferentially metabolize glucose via PPP pathway rather than glycolysis (Cetica et al., 2002).

Pig and dog oocytes utilize glucose as their primary energy substrate (Krisher et al., 2007; Songsasen \& Wildt, 2007). Recent study has shown that lipid metabolism plays significant roles in oocyte maturation in the pig (Sturmey \& Leese, 2003). This is not surprising since pig oocytes contain a substantial amount of triglyceride compared to other species (Sturmey $\&$ Leese, 2003). To date, there is no information on roles of intracellular lipid in dog oocyte development.

\section{Summary and future perspectives}

Energy metabolism is critical for oocyte maturation. Development of appropriate systems for in vitro oocyte maturation requires a great understanding of factors, including energy metabolism involved in the acquisition of oocyte developmental competence during folliculogenesis and during the maturation period. To date, studies have been focused on the impact of exogenous substrates, especially glucose and pyruvate on meiotic and cytoplasmic maturation. Very little attention has been centered on roles of intracellular lipid in oocyte development. Fatty acids are several-fold more energy rich than glucose. For example, 130 mols of ATP result from the oxidation of one mol of palmitic acid (C16:0), as compared to 38 mols of ATP from one mol of glucose. Thus, energy-dense lipids have potential ability to support and promote oocyte maturation and embryo development. Indeed, there has been increasing evidence that enhancing mitochondrial activity and $\beta$ oxidation lipid plays important role improve oocyte developmental competence in the mouse, a species that have small amount of intracellular lipids (Dunning et al., 2010). Furthermore, increase $\beta$-oxidation during in vitro folliculogenesis has been shown to promote mouse oocyte developmental competence (Dunning et al., 2011). Therefore, further research is needed to understand how the oocyte and early embryo utilize lipid substrates for energy production and whether this form of metabolism is developmentally beneficial. 
Certainly, there are species-specificities in oocyte metabolism. An in vitro condition developed for oocytes of a certain species cannot be directly applied to another. Thus, one of future research priorities should be advance our understanding about oocyte metabolic requirement for understudied species, especially carnivores. At last, current and future development of in vitro culture conditions for mammalian oocytes will certainly benefit from comparative studies conducted in different animal species.

\section{References}

Acton, B. M., Jurisicova, A. \& Casper, R. F. (2004) Alterations in mitochondrial membrane potential during preimplantation stages of mouse and human embryo development. Molecular Human Reproduction, 10, 23-32.

Albertini, D. F. \& Limback, S. D. (2009) The natural life cycle of the mammalian oocyte. In Borini, A. and Coticchio, G. (eds), Preservation of Human Oocytes. Informa Healthcare, London. pp. 83-94

Augustin, R., Pocar, P., Navarrete-Santos, A., Wrenzycki, C., Gandolfi, F., Niemann, H. \& Fischer, B. (2001) Glucose transporter expression is developmentally regulated in in vitro derived bovine preimplantation embryos. Molecular Reproduction and Development, 60, 370-376.

Bae, I.-H. \& Foote, R. H. (1974) Utilization of glutamine for energy and protein synthesis by cultured rabbit follicular oocytes. Experimental Cell Research, 90, 432-436.

Biggers, J. D., Whittingham, D. G. \& Donahue, R. P. (1967) The pattern of energy metabolism in the mouse oocyte and zygote. Proceedings of National Academy of Sciences USA, 58, 560-567.

Bilodeau-Goeseels, S. (2006) Effects of culture media and energy sources on the inhibition of nuclear maturation in bovine oocytes. Theriogenology, 66, 297-306.

Brinster, R. L. (1971) Oxidation of pyruvate and glucose by oocytes of the mouse and rhesus monkey. Journal of Reproduction and Fertility, 24, 187-191.

Cetica, P., Pintos, L., Dalvit, G. \& Beconi, M. (2002) Activity of key enzymes involved in glucose and triglyceride catabolism during bovine oocyte maturation in vitro. Reproduction, 124, 675-681.

Cetica, P., Pintos, L., Dalvit, G. \& Beconi, M. (2003) Involvement of enzymes of amino acid metabolism and tricarboxylic acid cycle in bovine oocyte maturation in vitro. Reproduction, 126, 753-763.

Colton, S. A., Pieper, G. M. \& Downs, S. M. (2002) Altered meiotic regulation in oocytes from diabetic mice. Biology of Reproduction, 67, 220-231.

Dan Goor, M., Sasson, S., Davarashvili A. \& Almagor, M. (1997) Expression of glucose transporter and glucose uptake in human oocytes and preimplantation embryos. Human Reproduction, 12, 2508-2510.

Dominko, T. \& First, N. L. (1997) Timing in meiotic progression in bovine oocytes and its effect on early embryo development. Molecular Reproduction and Development, 47, 456-467.

Downs, S. M. \& Hudson, E. D. (2000) Energy substrates and the completion of spontaneous meiotic maturation. Zygote, 8, 339-351.

Downs, S. M. \& Mastropolo, A. M. (1994) The participation of energy substrates in the control of meiotic maturation in murine oocytes. Developmental Biology, 162, 154168. 
Downs, S. M. \& Utecht, A. M. (1999) Metabolism of radiolabeled glucose by mouse oocytes and oocyte-cumulus cell complexes. Biology of Reproduction, 60, 1146-1452.

Downs, S. M. (1995) The influences of glucose, cumulus cells, and metabolic coupling on ATP levels and meiotic control in the isolated mouse oocytes. Developmental Biology, $167,502-512$.

Downs, S. M., Humpherson, P. G. \& Leese, H. J. (1998) Meiotic induction in cumulus cellenclosed mouse oocytes: involvement of the pentose phosphate pathway. Biology of Reproduction, 58, 1084-1094.

Downs, S. M., Humpherson, P. G. \& Leese, H. J. (2002) Pyruvate utilization by mouse oocytes is influenced by meiotic status and the cumulus oophorus. Molecular Reproduction and Development, 62, 113-123.

Downs, S. M., Mosey, J. L. \& Klinger, J. (2009) Fatty acid oxidation and meiotic resumption mouse oocytes. Molecular Reproduction and Development, 76, 844-853.

Dunning, K. R., Akison, L. K., Russell, D. L., Norman, R. J. \& Robker, R. L. (2011) Increased beta-oxidation and improved oocyte developmental competence in response to Lcarnitine during ovarian in vitro follicle development in mice. Biology of Reproduction, 85, 548-555.

Dunning, K. R., Cashman, K., Russell, D. L., Thompson, J. G., Norman, R. J. \& Robker, R. L. (2010) Beta oxidation is essential for mouse oocyte developmental competence. Biology of Reproduction, 83, 909-918.

Edson, M. A., Nagaraja, A. K. \& Matzuk, M. M. (2009) The mammalian ovary from genesis to revelation. Endocrine Review, 30, 624-712.

Edwards, R. G. \& Gates, A. H. (1959) Timing of the stages of the maturation divisions, ovulation, fertilization and the first cleavage of egg of adult mice treated with gonadotrophins. Journal of Endocrinology, 18, 292-304.

Engle, C. C., Foley, C. W., Plotka, E. D. \& Witherspoon, D. M. (1984) Free amino acids and protein concentrations in reproductive tract fluids of the mare. Theriogenology, 21, 919-930.

Eppig, J. J., O'Brien, M. O. \& Wigglesworth, K. (1996) Mammalian oocyte growth and development in vitro. Molecular Reproduction and Development, 44, 260-273.

Facecchia, K., Fochesato, L. A., Stohs, S. J. \& Pandey, S. (2011) Oxidative toxicity in neurodegenerative dieseases: role of mitochondrial dysfunction and therapeutic strategies. Journal of Toxicology, 683728, 1-12.

Ferguson, E. M. \& Leese, H. J. (1999) Triglyceride content of bovine oocytes and early embryos. Reproduction, 116, 373-378.

Ferguson, E. M. \& Leese, H. J. (2006) A potential role for tryglyceride as an energy sources during bovine oocyte maturation and early embryo development. Molecular Reproduction and Development, 73, 1195-1201.

Fujii, W. \& Funahashi, H. (2009) Exogenous adenosine reduces the mitochondrial membrane potential of murine oocytes during the latter half of in vitro maturation and pronuclear formation following chemical activation. Journal of Reproduction and Development, 55, 187-193.

Funahashi, H., Koike, T. \& Sakai, R. (2008) Effect of glucose and pyruvate on nuclear and cytoplasmic maturation of porcine oocytes in a chemically defined medium. Theriogenology, 70, 1041-1047. 
Garcia, J., Han, D., Sancheti, H., Yap, L. P., Kaplowitz, N. \& Cadenas, E. (2010) Regulation of mitochondrial glutathione redox status and protein glutathionylation by respiratory substrates. Journal of Biological Chemistry, 285, 39646-39654.

Gougeon, A. (2010) Human ovarian follicular development: From activation of resting follicles to preovulatory maturation. Annls d' Endocrinologie, 71, 132-143.

Griffin, J., Emery, B. R., Huang, I., Peterson, C. M. \& Carrell, D. T. (2006) Comparative analysis of follicle morphology and oocyte diameter in four mammalian species (mouse, hamster, pig and human). Journal of Experimental Clinical and Assisted Reproduction, $3,2$.

Harris, S. E., Gopichandran, N., Picton, H. M., Leese, H. J. \& Orsi, N. M. (2005) Nutrient concentrations in murine follicular fluid and the female reproductive tract. Theriogenology, 64, 992-1006.

Herrick, J. R., Brad, A. M. \& Krisher, R. L. (2006) Chemical manipulation of glucose metabolism in porcine oocytes: effects on nuclear and cytoplasmic maturation in vitro. Reproduction, 131, 289-298.

Hong, J. \& Lee, E. (2007) Intrafollicular amino acid concentration and the effect of amino acids in a defined maturation medium on porcine oocyte maturation, fertilization and preimplantation development. Theriogenology, 68, 728-735.

Hsieh, M., Thao, K. \& Conti, M. (2011) Genetic dissection of epidermal growth factor receptor signaling during luteinizing hormone-induced oocyte maturation. PLoS One, 6, e21574.

Jimena, P., Castilla, J., A., Peran, F., Ramirez, J. P., Gil, T. \& Mozas, J. (1993) Distribution of free amino acids in human preovulatory follicles. Hormone and Metabolism Research, $25,228-230$.

Jozwik, M., Jozwik, M., Teng, C. \& Battaglia, F. C. (2006) Amino acid, ammonia and urea concentration in human pre-ovulatory ovarian follicular fluid. Human Reproduction, $21,2776-2782$.

Kito, S. \& Bavister, B. D. (1997) Gonadotropins, serum, and amino acids alter nuclear maturation, cumulus expansion, and oocyte morphology in hamster cumulusoocyte complexes in vitro. Biology of Reproduction, 56, 1281-1289.

Krisher, R. L. \& Bavister, B. D. (1999) Enhanced glycolysis after maturation of bovine oocytes in vitro is associated with increased developmental competence. Molecular Reproduction and Development, 53, 19-26.

Krisher, R. L., Brad, A. M., Herrick, J. R., Sparman, M. L. \& Swain, J. E. (2007) A comparative analysis of metabolism and viability in porcine oocytes during in vitro maturation. Animal Reproduction Science, 98, 72-96.

Leese, H. J. \& Ferguson, E. M. (1999) Triglyceride content of bovine oocytes and early embryos. Journal of Reproduction and Fertility, 116, 373-378.

Loewenstein, J. E. \& Cohen, A. (1964) Dry mass, lipid content and protein content of the intact and zona--free mouse ovum. Journal Embryology Experiment and Morphology, $12,113-121$.

McEvoy, T. G., Coull, G. D., Broadbent, P. J., Hutchinson, J. S. \& Speake, B. K. (2000) Fatty acid composition of lipids in immature cattle, pig and sheep oocytes with intact zona pellucida. Journal of Reproduction and Fertility, 118, 163-170. 
Newsholme, P., Lima, M. M. R., Procopio, J., Pithon-Curi, T. C., Doi, S. Q., Bazotte, R. B. \& Curi, R. (2003) Glutamine and glutamate as vital metabolites. Brazilian Journal of Medical and Biological Research, 36, 153-163.

Orsi, N. M., Gopichandran, N., Leese, H. J., Picton, H. M. \& Harris, S. E. (2005) Fluctuations in bovine ovarian follicular fluid throughout the oestrous cycle: a comparison with plasma and a TCM-199-based maturation medium. Reproduction, 129, 229-334.

Ott, M., Gogvadze, V., Orrenious, S. \& Zhivotovsky, B. (2007) Mitochondria, oxidative stress and cell death. Apoptosis, 12, 913-922.

Perrelli, M.-G., Pagliaro, P. \& Penna, C. (2011) Ischemia/reperfusion injury and cardioprotective mechanisms: role of mitochondria and reactive oxygen species. World Journal of Cardiology, 3, 186-200.

Peter, H. \& McNatty, K. P. (1980) The Ovary, University of California Press, Berkley and Los Angeles. 175 pp.

Picton, H. M. (2001) Activation of follicle development: the primordial follicle. Theriogenology, 55, 1193-1210.

Pisani, L., F., Antonini, S., Pocar, P., Ferrari, S., Brevini, T. A., Rhind, S. M. \& Gandolfi, F. (2008) Effects of pre-mating nutrition on mRNA levels of developmentally relevant genes in sheep oocytes and granulosa cells. Reproduction, 136, 303-312.

Purcell, S. H. \& Moley, K. H. (2009) Glucose transporters in gametes and preimplantation embryos. Trends in Endocrinology and Metabolism, 20, 483-489.

Ramalho-Santos, J., Varum, S., Amaral, S., Mota, P. C., Sousa, A. P. \& Amaral, A. (2009) Mitochondrial functionality in reproduction: from gonads and gametes to embryos and embryonic stem cells. Human Reproduction Update, 15, 553-572.

Reynaud, K., Fontbonne, A., Marseloo, N., Thoumire, S., Chebrout, M., de Lesegno, C. V. \& Chastant-Maillard, S. (2005) In vivo meiotic resumption, fertilization and early embryonic development in the bitch. Reproduction, 130, 193-201.

Reynaud, K., Gicquel, C., Thoumire, S., Chebrout, M., Ficheux, C., Bestandji, M. \& ChastantMaillard, S. (2009) Folliculogenesis and morphometry of oocyte and follicle growth in the feline ovary. Repro Domes Anim, 44, 174-179.

Rieger, D. \& Loskutoff, N. M. (1994) Changes in the metabolism of glucose, pyruvate, glutamine and glycine during maturation of cattle oocytes in vitro. Journal of Reproduction and Fertility, 100, 257-262.

Roberts, R., Stark, J., Latropoulou, A., Becker, D. L., Franks, S. \& Hardy, K. (2004) Energy substrate metabolism of mouse cumulus-oocyte complexes: response to folliclestimulating hormone is mediated by the phosphatidylinositol 3-kinase pathway and is associated with oocyte maturation. Biology of Reproduction, 71, 199-209.

Sato, H., Iwata, H., Hayashi, T., Kimura, K., Kuwayama, T. \& Monji, Y. (2007) The effect of glucose on the progression of the nuclear maturation of pig oocytes. Animal Reproduction Science, 99, 299-305.

Somfai, T., Kaneda, M., Akagi, S., Watanabe, S., Haraguchi, S., Mizutani, E., Dang-Nguyen, T. Q., Geshi, M., Kikuchi, K. \& Nagai, T. (2011) Enhancement of lipid metabolism with L-carnitine during in vitro maturation improves nuclear maturation and cleavage ability of follicular porcine oocytes. Reproduction Fertility and Development, 23, 912-920.

Son, W. Y., Das, M., Shalom-Paz, E. \& Holzer, H. (2011) Mechanisms of follicle selection and development. Minerva Ginecologica, 63, 89-102. 
Songsasen, N. \& Wildt, D. E. (2007) Oocyte biology and challenges in developing in vitro maturation systems in the domestic dog. Animal Reproduction Science, 98, 2-22.

Songsasen, N., Fickes, A., Pukazhenthi, B. S. \& Wildt, D. E. (2009) Follicular morphology, oocyte diameter and localization of fibroblast growth factors in the domestic dog ovary. Reproduction in Domestic Animals, 44 (Suppl 2), 65-70.

Songsasen, N., Spindler, R. E. \& Wildt, D. E. (2007) Requirement for, and patterns of, pyruvate and glutamine metabolism in the domestic dog oocyte in vitro. Molecular Reproduction and Development, 74, 870-877.

Songsasen, N., Wesselowski, S., Carpenter, J. W., Wildt, D. E. (2012) The ability to achieve meiotic maturation in the dog oocyte is linked to glycolysis and glutamine oxidation. Molecular Reproduction and Development, in press.

Spindler, R. E., Pukazhenthi, B. S. \& Wildt, D. E. (2000) Oocyte metabolism predicts the development of cat embryos to blastocyst in vitro. Molecular Reproduction and Development, 56, 163-171.

Steeves, T. E. \& Gardner, D. K. (1999) Metabolism of glucose, pyruvate and glutamine during the maturation of oocytes derived from pre-pubertal and adult cows. Molecular Reproduction and Development, 54, 92-101.

Sturmey, R. G. \& Leese, H. J. (2003) Energy metabolism in pig oocytes and early embryos. Reproduction, 126, 197-204.

Sturmey, R. G., O'Toole, P. J. \& Leese, H. J. (2006) Fluorescence resonance energy transfer analysis of mitochondrial lipid association in the porcine oocyte. Reproduction, 132, 829-837.

Sturmey, R. G., Reis, A., Leese, H. J. \& McEvoy, T. G. (2009) Role of fatty acids in enery provision during oocyte maturation and early embryo development. Reproduction of Domestic Animals, 44, 50-58.

Sun, Q. Y., Miao, Y. L. \& Schatten, H. (2009) Towards a new understanding on the regulation of mammalian oocyte meiotic resumption. Cell Cycle, 8, 2741-2747.

Sun, Q. Y., Wu, G. M., Lai, L., Park, K. W., Cabot, R., Cheong, H. T., Day, B. N., Prather, R. S. \& Schatten, H. (2001) Translocation of active mitochondria during pig oocyte maturation, fertilization and early embryo development in vitro. Reproduction, 122, 155-163.

Sutton, M. L., Gilchrist, R. B. \& Thompson, J. G. (2003) Effects of in-vivo and in-vitro environments on the metabolism of the cumulus-oocyte complex and its influence on oocyte developmental capacity. Human Reproduction Update, 9, 35-48.

Sutton-McDowall, M. L., Gilchrist, R. B. \& Thompson, J. G. (2010) The pivotal role of glucose metabolism in determining oocyte developmental competence. Reproduction, 139, 685-695.

Tingen, C., Kim, A. \& Woodruff, T. K. (2009) The primordial pool of follicles and nest breakdown in mammalian ovaries. Molecular Human Reproduction, 15, 795-803.

Urner, F. \& Sakkas, D. (2005) Involvement of the pentose phosphate pathway and redox regulation in fertilization in the mouse. Molecular Reproduction and Development, 70, 494-503.

Van Blerkom, J. \& Davis, P. (2007) Mitochondrial signaling and fertilization. Molecular Human Reproduction, 13, 759-779. 
Van Blerkom, J. (2004) Mitochondria in human oogenesis and preimplantation embryogenesis: engines of metabolism, ionic regulation and developmental competence. Reproduction, 128, 269-280.

Van Blerkom, J., Davis, P. \& Alexander, S. (2003) Inner mitochondrial membrane potential (DYm), cytoplasmic ATP content and free $\mathrm{Ca}^{2+}$ levels in metaphase II mouse oocytes. Human Reproduction, 18, 2429-2440.

Van Blerkom, J., Davis, P., Mathwig, V. \& Alexander, S. (2002) Domains of high-polarized and low-polarized mitochondria may occur in mouse and human oocytes and early embryos. Human Reproduction, 17, 393-406.

Voet, D. \& Voet, J. G. (2004) Biochemistry. 3 edn, John, Wiley \& Sons, Inc., Hoboken, NJ. 1591 pp.

Wang, Q., Frolova, A. I., Purcell, S., Adastra, K., Schoeller, E., Chi, M. M., Schedl, T. \& Moley, K. H. (2010) Mitochondrial dysfunction and apoptosis in cumulus cells of type I diabetic mice. PLoS One, 5, e15901.

Watson, A. J. (2007) Oocyte cytoplasmic maturation: A key mediator of oocyte and embryo developmental competence. Journal of Animal Sciences, 85 (E. Suupl.), E1-E3.

Watson, A. J., de Sousa, P., Caveney, A., Barcroft, L., Natale, D., Urquhart, J. \& Westhusin, M. E. (2000) Impact of bovine oocyte maturation media on oocyte transcript levels, blastocyst development, cell number, and apotosis. Biology of Reproduction, 62, 355364.

Yu, Y., Dumollard, R., Rossbach, A., Lai, F. A. \& Swann, K. (2010) Redistribution of mitochondria leads to bursts of ATP production during spontaneous mouse oocyte maturation. Journal of Cellular Physiology, 224, 672-680.

Zheng, P., Bavister, B. D. \& Ji, W. (2001) Energy substrate requirement for in vitro maturation of oocytes from unstimulated adult rhesus monkeys. Molecular Reproduction and Development, 58, 348-355.

Zheng, P., Bavister, B. D. \& Ji, W. Z. (2002) Amino acid requirements for maturation of rhesus monkey (Macacca mulatta) oocytes in culture. Reproduction, 124, 515-522.

Zheng, P., Vassena, R. \& Latham, K. E. (2007) Effects of in vitro oocyte maturation and embryo culture on the expression of glucose transporters, glucose metabolism and insulin signaling genes in rhesus money oocytes and preimplantation embryos. Molecular Human Reproduction, 13, 361-371.

Zuelke, K. A. \& Brackett, B. G. (1992) Effects of luteinizing hormone on glucose metabolism in cumulus-enclosed bovine oocytes matured in vitro. Endocrinology, 131, 2690-2696.

Zuelke, K. A. \& Brackett, B. G. (1993) Increased glutamine metabolism in bovine cumulus cell-enclosed and denuded oocytes after in vitro maturation with lutenizing hormone. Biology of Reproduction, 48, 815-820. 


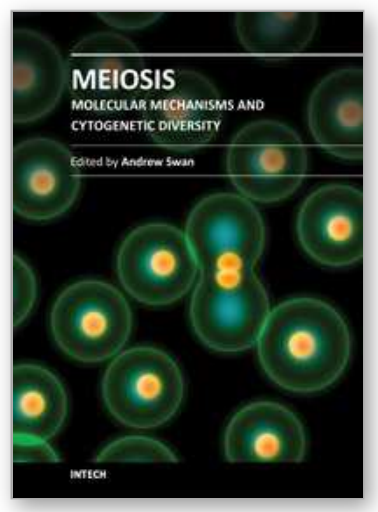

\author{
Meiosis - Molecular Mechanisms and Cytogenetic Diversity \\ Edited by Dr. Andrew Swan
}

ISBN 978-953-51-0118-5

Hard cover, 472 pages

Publisher InTech

Published online 29, February, 2012

Published in print edition February, 2012

Meiosis, the process of forming gametes in preparation for sexual reproduction, has long been a focus of intense study. Meiosis has been studied at the cytological, genetic, molecular and cellular levels. Studies in model systems have revealed common underlying mechanisms while in parallel, studies in diverse organisms have revealed the incredible variation in meiotic mechanisms. This book brings together many of the diverse strands of investigation into this fascinating and challenging field of biology.

\title{
How to reference
}

In order to correctly reference this scholarly work, feel free to copy and paste the following:

N. Songsasen (2012). Energy Metabolism Regulating Mammalian Oocyte Maturation, Meiosis - Molecular Mechanisms and Cytogenetic Diversity, Dr. Andrew Swan (Ed.), ISBN: 978-953-51-0118-5, InTech, Available from: http://www.intechopen.com/books/meiosis-molecular-mechanisms-and-cytogenetic-diversity/energymetabolism-regulating-mammalian-oocyte-maturation

\section{INTECH}

open science | open minds

\section{InTech Europe}

University Campus STeP Ri

Slavka Krautzeka 83/A

51000 Rijeka, Croatia

Phone: +385 (51) 770447

Fax: +385 (51) 686166

www.intechopen.com

\section{InTech China}

Unit 405, Office Block, Hotel Equatorial Shanghai

No.65, Yan An Road (West), Shanghai, 200040, China

中国上海市延安西路65号上海国际贵都大饭店办公楼 405 单元

Phone: +86-21-62489820

Fax: +86-21-62489821 
(C) 2012 The Author(s). Licensee IntechOpen. This is an open access article distributed under the terms of the Creative Commons Attribution 3.0 License, which permits unrestricted use, distribution, and reproduction in any medium, provided the original work is properly cited. 